\title{
Differential vulnerability of basal forebrain cholinergic and NADPH diaphorase cells to ibotenate and quisqualate
}

\author{
CHERYL A. HARRINGTON and GARY L. WENK \\ Arizona Research Laboratories Division of Neural Systems, Memory \& Aging, \\ University of Arizona, Tucson, Arizona
}

\begin{abstract}
Central neurons demonstrate a differential vulnerability to the cytotoxic effects of glutamate analogues. The cytotoxicity of agonists such as ibotenate (IBO) or quisqualate (QUIS) depend upon at least three different mechanisms: agonist properties at glutamate receptors, their ability to block a neuronal glutamate/cystine transporter, or their ability to generate nitric oxide. We manipulated the cytotoxicity of IBO and QUIS in the rat basal forebrain by altering their concentration or by coinjecting IBO with specific agents: cystine to overcome the glutamate/cystine exchange blockade; zinc to attenuate IBO's actions at the receptor; muscimol to attenuate regional excitatory actions; or 2-chloroadenosine to decrease local endogenous glutamate release. Coinjection of IBO with zinc or cystine spared selected populations of basal forebrain cholinergic cells. Injection of QUIS, but not IBO, destroyed NADPH $(+)$ cells. The pattern of cell loss may be related to the ability of different glutamate analogues to produce nitric oxide.
\end{abstract}

In studies aimed at understanding structure/function relationships, excitotoxins are frequently used to produce lesions. The use of conformationally restricted analogues of the amino acid neurotransmitter glutamate-for example, ibotenic (IBO), kainic (KA), or quisqualic (QUIS) acids-provides the investigator with a method by which cell bodies within the brain region of interest can be destroyed, without harming the fibers of passage (Coyle \& Schwarcz, 1983).

One region that has been extensively investigated using this method is the basal forebrain (for a review, see Olton $\&$ Wenk, 1987). This region includes the vertical and horizontal limbs of the nucleus of the diagonal band of Broca, the substantia innominata, and the ventral pallidum (Mesulam, Mufson, Levey, \& Wainer, 1983). Degeneration of the cholinergic cells within this region is thought to play an important role in the cognitive deficits seen in $\mathrm{Al}$ zheimer's disease (Bartus, Dean, Beer, \& Lippa, 1982; Coyle, Price, \& DeLong, 1983). Animal models of basal forebrain degeneration are most frequently produced by microinjection of IBO, KA, or QUIS (Olton \& Wenk, 1987). The cytotoxicity of each glutamate analogue may be determined by the presence of the appropriate subclass of glutamate receptor to which it is an agonist (Araki, P. L. McGeer, \& E. G. McGeer, 1985; Nadler, Evenson, $\&$ Cuthbertson, 1981). For example, QUIS is an agonist

This research was supported by Grant BNS 89-14941 from the National Science Foundation to G.L.W. The authors thank Sherri Mobley for excellent technical assistance. Correspondence should be addressed to G. L. Wenk, Division of Neural Systems, Memory \& Aging, University of Arizona, 384 Life Sciences North, Tucson, AZ 85724 (fax, 602-626-2618; e-mail, gwenk@ccit.ariz.edu.internet). at the glutamate receptor that is also sensitive to alphaamino-3-hydroxy-5-methyl-4-isoxazole proprionic acid (AMPA), whereas IBO is primarily an agonist at the $\mathrm{N}$ methyl-d-aspartate (NMDA)-sensitive glutamate receptor.

Central neurons demonstrate a differential vulnerability to the cytotoxic effects of various glutamate analogues (Araki et al. 1985; Perkins \& Stone, 1983; Schwarcz \& Kohler, 1983; Waldvogel, Faull, Williams, \& Dragunow, 1991; Wenk, Markowska, \& Olton, 1989) -that is, specific brain regions and cell types are far more sensitive to one toxin than another (Beal, Kowall, Swartz, Ferrante, \& Martin, 1989). For example, quinolinic acid, IBO, and QUIS destroy basal forebrain cholinergic cells, but quinolinic acid and QUIS do not destroy medial septal area cholinergic cells (Schwarcz \& Kohler, 1983).

Both IBO and QUIS destroy a significant population of cholinergic cells in the basal forebrain, although QUIS may be more effective than IBO (Wenk, Harrington, Tucker, Rance, \& Walker, 1992; Wenk et al., 1989; the present study). Recent studies that have compared the behavioral effects of basal forebrain lesions produced by IBO or QUIS (Connor, Langlais, \& Thal, 1991; Riekkinen, Riekkinen, \& Riekkinen, 1991; Robbins et al., 1989) have concluded that the degree of memory impairment is not related to the degree of cholinergic cell loss. A complete understanding of the biochemical mechanisms by which IBO produces a significant and long-lasting memory impairment, while QUIS does not, may ultimately lead to an effective pharmacotherapy for age-related disorders that are associated with neuronal degeneration.

The biochemical mechanisms underlying the cytotoxic effects of IBO may depend on at least three different actions: its agonist properties at glutamate receptors, its abil- 
ity to block the neuronal glutamate/cystine (CYS) transport exchange system (Murphy, Schnaar, \& Coyle, 1990), or its ability to generate nitric oxide (NO; Dawson, Dawson, London, Bredt, \& Snyder, 1991; Kiedrowski, Costa, \& Wroblewski, 1992). Prolonged activation of NMDA-sensitive receptors by IBO results in an influx of chloride and calcium ions into the neuron (Rothman \& Olney, 1987). This leads to excess water entry and osmotic lysis, as well as calcium-induced mitochondrial dysfunction and altered protease and lipase activation (Choi, 1987). Activation of the NMDA receptor also leads to the production of NO by the conversion of arginine to citrulline (Dawson et al., 1991; Kiedrowski et al., 1992). In contrast to IBO, QUIS did not lead to the production of NO when applied to cultures of cerebellar or cortical neurons (Frandsen, Anderson, \& Schousboe, 1991; Kiedrowski et al., 1992). The presence of zinc ( $\mathrm{Zn}$ ) ions can attenuate the activation of NMDA receptors and the cytotoxicity of glutamate analogues (Peters, Koh, \& Choi, 1987; Westbrook \& Mayer, 1987; Yeh, Bonhaus, \& McNamara, 1990).

IBO also blocks the exchange of extracellular CYS with intracellular glutamate (Murphy et al., 1990). CYS is a required precursor in the synthesis of the free radical scavenger glutathione. By blocking CYS entry into the neuron, IBO depletes intracellular levels of glutathione and makes the neuron more sensitive to oxidative stress (Bridges, Koh, Hatalski, \& Cotman, 1991), a condition possibly exacerbated by the actions of excitatory amino acids at glutamate receptors. The cytotoxic effect of QUIS may also depend upon the inhibition of neuronal cystine uptake (Murphy, Miyamoto, Sastre, Schnaar, \& Coyle, 1989), but not on the excessive influx of calcium and chloride ions (Garthwaite \& Garthwaite, 1989). The differential actions of QUIS and IBO on cellular chemistry may explain why these neurotoxins produce different patterns of neuronal degeneration (Garthwaite \& Garthwaite, 1991; Page, Everitt, Robbins, Marston, \& Wilkinson, 1991; Robbins et al., 1989). Furthermore, IBO may be associated with a greater memory impairment than QUIS because of its ability to simultaneously generate more cytotoxic products (e.g., NO) and compromise each neuron's ability to scavenge for free radicals.

In the present study, we manipulated the cytotoxicity of IBO and QUIS either by altering the concentration of each toxin or by coinjecting IBO with an agent that attenuates its actions: CYS to overcome the blockade of the glutamate/CYS exchange system (Murphy et al., 1990); $\mathrm{Zn}$ to attenuate the actions of IBO at the NMDA receptor (Peters et al., 1987; Westbrook et al., 1987; Yeh et al., 1990); muscimol (MUS), a GABAergic agonist that may attenuate the regional excitatory influence of IBO; or 2-chloroadenosine (CHA), an adenosine receptor agonist that may decrease local endogenous glutamate release and attenuate IBO's cytotoxicity (Finn, Swartz, \& Beal, 1991). The loss of cortical choline acetyltransferase (ChAT) activity, a specific marker for cholinergic cells and terminals, was used as a standard measure of the effectiveness of basal forebrain lesions (Wenk, Cribbs, \& McCall, 1984).

Throughout various regions of the central nervous system, select populations of neurons can be stained for nicotinamide adenine dinucleotide phosphate diaphorase (NADPH-diaphorase) activity (Vincent \& Kimura, 1992); these neurons are now thought to generate the messenger molecule NO (Vincent \& Hope, 1992). Recent evidence suggests that central neurons containing NADPH-diaphorase activity are differentially vulnerable to the effects of IBO and QUIS. For example, NADPH-positive [NADPH(+)] cortical neurons in culture were resistant to damage by NMDA agonists but were selectively destroyed by QUIS (Koh \& Choi, 1988). In the rostral portion of the basal forebrain, NADPH-diaphorase coexists with ChAT (Pasqualotto \& Vincent, 1991) and somatostatin and Neuropeptide Y (Vincent et al., 1983). We therefore examined the differential vulnerability of NADPH( + ) basal forebrain cells to IBO and QUIS.

\section{METHOD}

\section{Subjects}

Male Fischer 344 rats (aged 3 months) were doubly housed in plastic cages with ad-lib food and water on a 12:12 day:night cycle (lights on at $0700 \mathrm{~h}$ ).

\section{Surgical Methods}

Each rat was first given $0.3 \mathrm{ml}$ of atropine methylbromide $(1.5 \mathrm{mg} / \mathrm{ml}$, i.p.) and then anesthetized with sodium pentobarbital $(50 \mathrm{mg} / \mathrm{kg}$, i.p.). The rat was placed in a stereotaxic instrument (Model 900, David Kopf, Tujunga, CA), with the incisor bar set $2 \mathrm{~mm}$ below the earbars, and the scalp was incised and retracted. Holes were drilled in appropriate locations in the skull with a dental drill. Coordinates for the lesions were 0.4 and $0.8 \mathrm{~mm}$ posterior to Bregma, $2.8 \mathrm{~mm}$ lateral from the midline, and $6.8 \mathrm{~mm}$ below the dorsal surface of the neocortex. The neurotoxins were slowly $(0.1 \mu \mathrm{l} / \mathrm{min})$ injected $(0.5 \mu \mathrm{l} / \mathrm{site})$, and the needle (Model $7001-\mathrm{N}$, Hamilton) was left in place $5 \mathrm{~min}$ to limit diffusion. Unilateral lesions were produced by injection of one of the following toxins, prepared in phosphate-buffered saline $(0.9 \%)$, into the left basal forebrain region: IBO (0.063 or $0.03 \mathrm{M}, \mathrm{pH} 7.7)$; IBO/CYS (0.063 M/1.15 mM, pH 7.7); IBO/MUS (0.063 M/0.44 mM, pH 7.7); IBO/Zn (0.063 M/1.0 mM, pH 7.7); IBO/CHA $(0.03 \mathrm{M} /$ $25 \mathrm{mM}, \mathrm{pH} 7.7$ ); or QUIS $(0.12,0.06$, or $0.03 \mathrm{M}$, pH 7.4).

\section{Histochemical Methods}

Two weeks after surgery, each rat was sacrificed by decapitation. The brain was removed and placed in a Brain Matrix (Model RBM-4000C, Activational Systems, Warren, MI) for dissection. A coronal section (approximately $1.0 \mathrm{~mm}$ thick) was taken to include the entire basal forebrain region. The most anterior extent of the slab was the anterior commissure. These coronal slabs were fixed by immersion in $4 \%$ paraformaldehyde buffered with $0.1-\mathrm{M}$ sodium phosphate, pH 7.4, for 6 hours. The slabs were then removed and placed in $30 \%$ sucrose until they sank, after which they were frozen $\left(-80^{\circ} \mathrm{C}\right)$. Forty-micrometer sections were cut on a freezing microtome and collected in 0.1-M sodium phosphate buffer. The sections were then stained for diaphorase activity using a modified method of Scherer-Singler, Vincent, Kimura, and E. G. McGeer (1983). Briefly, free-floating sections were incubated for $1 \mathrm{~h}$ in 0.1-M Tris-HCL, pH 8.0, containing 1.0-mM NADPH, 0.2-mM nitroblue tetrazolium, $0.04 \%$ Tween-80, $0.1 \%$ Triton-X 100, 1.0-mM 
magnesium chloride, and 15-mM sodium maleate (Sigma Chem. Co., St. Louis)

\section{Biochemical Methods}

Cortical samples were taken from the frontolateral/sensorimotor (anterior) and parietal/occipital (posterior) cortex and analyzed for ChAT activity in order to estimate the extent of the lesion with the loss of basal forebrain cholinergic cells. The basal forebrain contains many cholinergic neurons distributed throughout its entire anterior-posterior extent (Mesulam et al., 1983). These neurons provide a topographically organized innervation of the entire cortical mantle (Lamour, Dutar, \& Jobert, 1982; Mesulam et al., 1983; Rye, Wainer, Mesulam, Mufson, \& Saper, 1984). ChAT activity was measured by the formation of ${ }^{14} \mathrm{C}$-acetylcholine formed from $\left[{ }^{14} \mathrm{C}\right]$-acetylcoenzyme-A and choline, according to the method of Fonnum (1969). Protein content was determined by the method of Lowry, Rosenbrough, Farr, and Randall (1951), with bovine serum albumin (BSA) as the protein standard.

\section{RESULTS}

\section{Biochemistry}

QUIS, at all three concentrations, or IBO, alone or in combination with MUS, CYS, or CHA, significantly $(p<.05$ to $p<.01)$ decreased ChAT activity in the anterior (frontolateral) cortex (see Table 1), relative to the unlesioned side. Coinjection of IBO with $1.0-\mathrm{mM}$ Zn produced no significant difference in ChAT activity, relative to the control side. Coinjection of IBO with CYS, $\mathrm{Zn}$, MUS, or CHA produced a somewhat smaller decrease in cortical ChAT activity, relative to IBO, but only coinjection with $\mathrm{Zn}$ was able to protect a large enough population of cholinergic cells so that the ChAT loss was no longer significantly different from the unlesioned side. Injection of 0.12 -M QUIS produced a significantly $(p<$ .01) greater decrease in cortical ChAT activity, relative to all other groups. In posterior (parietal-occipital) cortex, only the coinjection of CHA with IBO and the highest dose of QUIS $(0.12 \mathrm{M})$ significantly $(p<.05)$ decreased ChAT activity. In contrast, in posterior cortex, coinjection of IBO with Zn, MUS, or CYS tended to produce a much smaller loss in ChAT activity, relative to IBO alone.

\section{Histology}

NADPH $(+)$ cells showing moderate to dense staining were observed on the unlesioned side in the both the vertical and the horizontal limbs of the nucleus of the diagonal band of Broca, throughout the caudate-putamen and within the fundus striatum, as well as within the bed nucleus of the stria terminalis, the nucleus of the lateral olfactory tract, and the region dorsal to the supraoptic nucleus; a small population of densely stained cells were also distributed sparsely among the Islands of Calleja and the nuclei of the amygdala, particularly the medial and cortical amygdaloid nuclei. The dorsal and ventral pallidum and substantia innominata region contained very few $\mathrm{NADPH}(+)$ cells. A qualitative examination of the lesioned side, relative to the intact side, revealed that injection of QUIS (Figure 1), but not IBO (Figure 2), into the basal forebrain was associated with a significant loss of NADPH(+) cells throughout the extent of the injection, including cells within the horizontal limb of the diagonal band, ventral caudate-putamen, bed nucleus of the stria terminalis, and ventrolateral basal forebrain region.

\section{DISCUSSION}

The results of this experiment demonstrate our ability to manipulate the cytotoxicity of IBO and QUIS by altering their concentration or coinjecting with $\mathrm{CYS}, \mathrm{Zn}$, CHA, or MUS. Coinjection of IBO with $\mathrm{Zn}$ or CYS may have spared selected populations of basal forebrain cholinergic cells, particularly those that project to the posterior cortical areas. Previous investigations have shown that basal forebrain cells are differentially vulnerable to the effects of IBO and QUIS. In behavioral studies, injection of either toxin into the basal forebrain produced a significant cortical ChAT loss, but only IBO produced

Table 1

Cortical Choline Acetyl Transferase Activity

\begin{tabular}{|c|c|c|c|c|c|c|c|c|c|c|}
\hline & \multicolumn{5}{|c|}{ Anterior Cortex } & \multicolumn{5}{|c|}{ Posterior Cortex } \\
\hline & \multicolumn{2}{|c|}{ Right } & \multicolumn{2}{|c|}{ Left } & \multirow{2}{*}{$\begin{array}{c}\% \\
\text { Change }\end{array}$} & \multicolumn{2}{|c|}{ Right } & \multicolumn{2}{|c|}{ Left } & \multirow{2}{*}{$\begin{array}{c}\% \\
\text { Change }\end{array}$} \\
\hline & $M$ & $S E$ & $M$ & $S E$ & & $M$ & $S E$ & $M$ & $S E$ & \\
\hline IBO & 38.3 & 5.2 & 19.2 & 2.3 & $-49.8 \dagger$ & 35.5 & 3.3 & 39.1 & 2.8 & -17.9 \\
\hline $\mathrm{IBO} / \mathrm{Zn}$ & 18.5 & 1.8 & 13.6 & 1.6 & -26.0 & 20.9 & 5.5 & 21.5 & 2.1 & +2.6 \\
\hline IBO/MUS & 53.5 & 4.5 & 35.0 & 5.9 & $-34.5^{*}$ & 42.9 & 4.6 & 41.0 & 5.8 & +4.3 \\
\hline IBO/CYS & 47.1 & 4.9 & 33.6 & 4.7 & $-28.5^{*}$ & 34.5 & 4.3 & 32.6 & 3.8 & -5.4 \\
\hline IBO.03M & 42.7 & 2.7 & 24.9 & 0.5 & $-41.8 \dagger$ & 48.9 & 5.2 & 39.9 & 5.0 & -18.5 \\
\hline IBO/CHA & 49.9 & 4.6 & 33.5 & 5.4 & $-32.9^{*}$ & 58.6 & 7.9 & 40.9 & 6.1 & $-30.1^{*}$ \\
\hline QUIS.12M & 45.3 & 9.6 & 15.8 & 3.7 & $-65.1 \ddagger$ & 53.7 & 9.5 & 25.5 & 4.1 & $-52.5^{*}$ \\
\hline QUIS.06M & 40.2 & 5.8 & 26.1 & 2.7 & $-35.1^{*}$ & 39.9 & 5.7 & 34.3 & 4.1 & -14.2 \\
\hline QUIS.03M & 37.2 & 4.3 & 25.4 & 4.0 & $-31.9 *$ & 44.6 & 8.4 & 38.9 & 3.2 & -12.8 \\
\hline
\end{tabular}

Note-Data are expressed as mean $(M)$ and standard error of the mean (SE) nanomoles of Ach formed/hour/milligrams protein. \% Change $=$ percent change versus the contralateral side. IBO $=$ ibotenic acid $0.06 \mathrm{M}(n=10) ; \mathrm{IBO} / \mathrm{Zn}=\mathrm{IBO}+$ zinc $1.0 \mathrm{mM}(n=3) ; \mathrm{IBO} / \mathrm{MUS}=\mathrm{IBO}+$ muscimol $0.44 \mathrm{mM}$ $(n=7) ; \mathrm{IBO} / \mathrm{CYS}=\mathrm{IBO}+$ cystine $1.15 \mathrm{mM}(n=7) ; \mathrm{BBO} / \mathrm{CHA}=$ ibotenic acid $30 \mathrm{mM}+2$-chloroadenosine $25 \mathrm{mM}(n=5)$; IBO $0.03 \mathrm{M}=$ ibotenic acid $30 \mathrm{mM}(n=4)$; QUIS at three different molar concentrations $(n=9) . \quad{ }^{*} p<.05 . \quad \dagger p<.01, \mathrm{~L}$ versus $\mathrm{R}$. Lesions were produced on the left side of each rat. $\ddagger p<.01$, versus all other groups. 

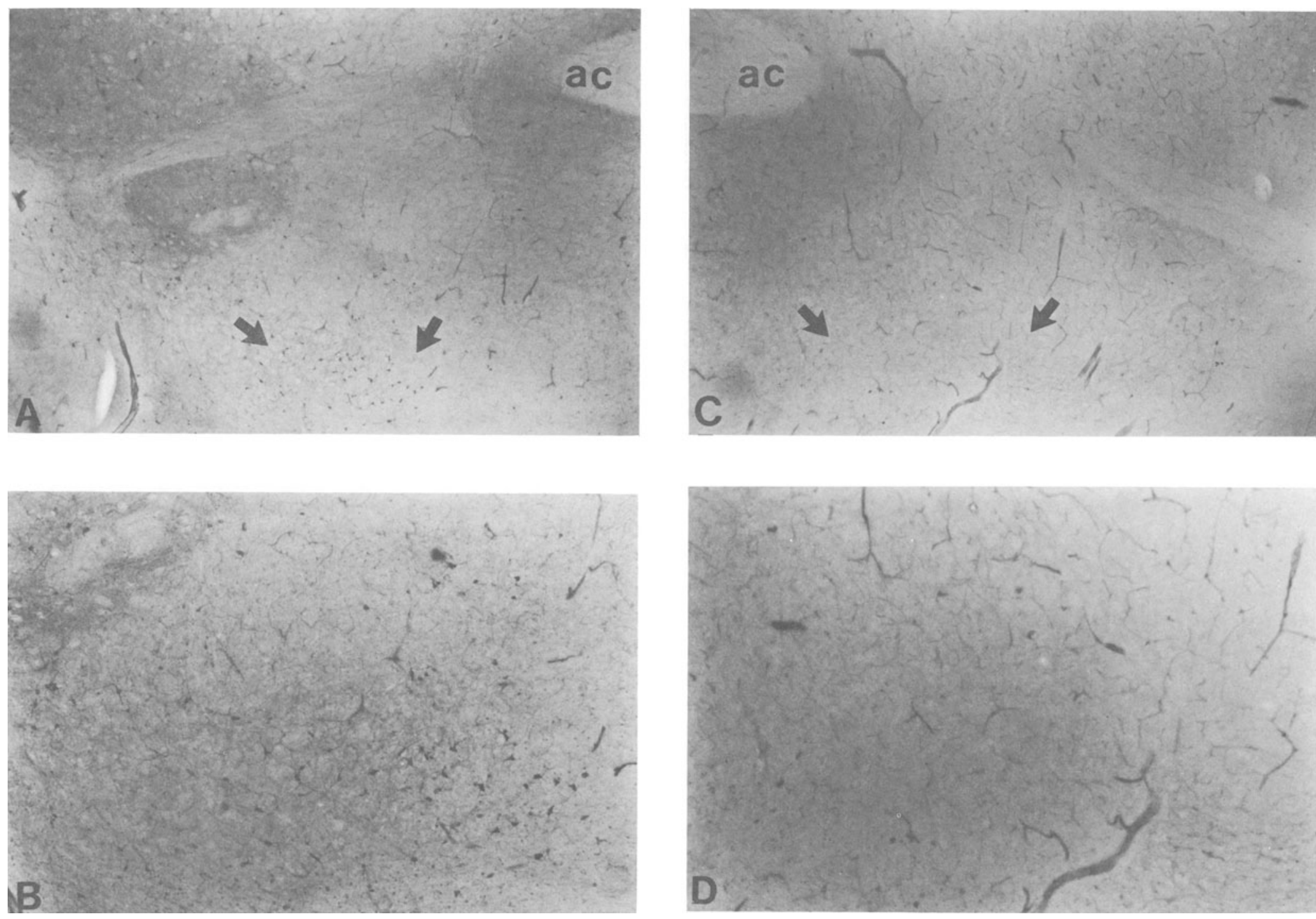

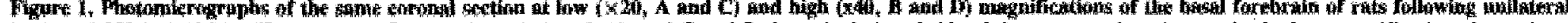

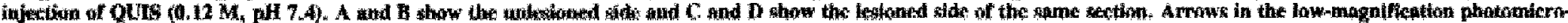

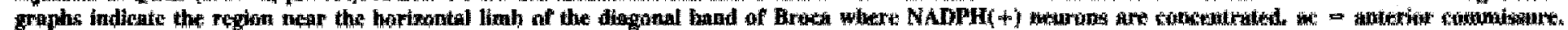



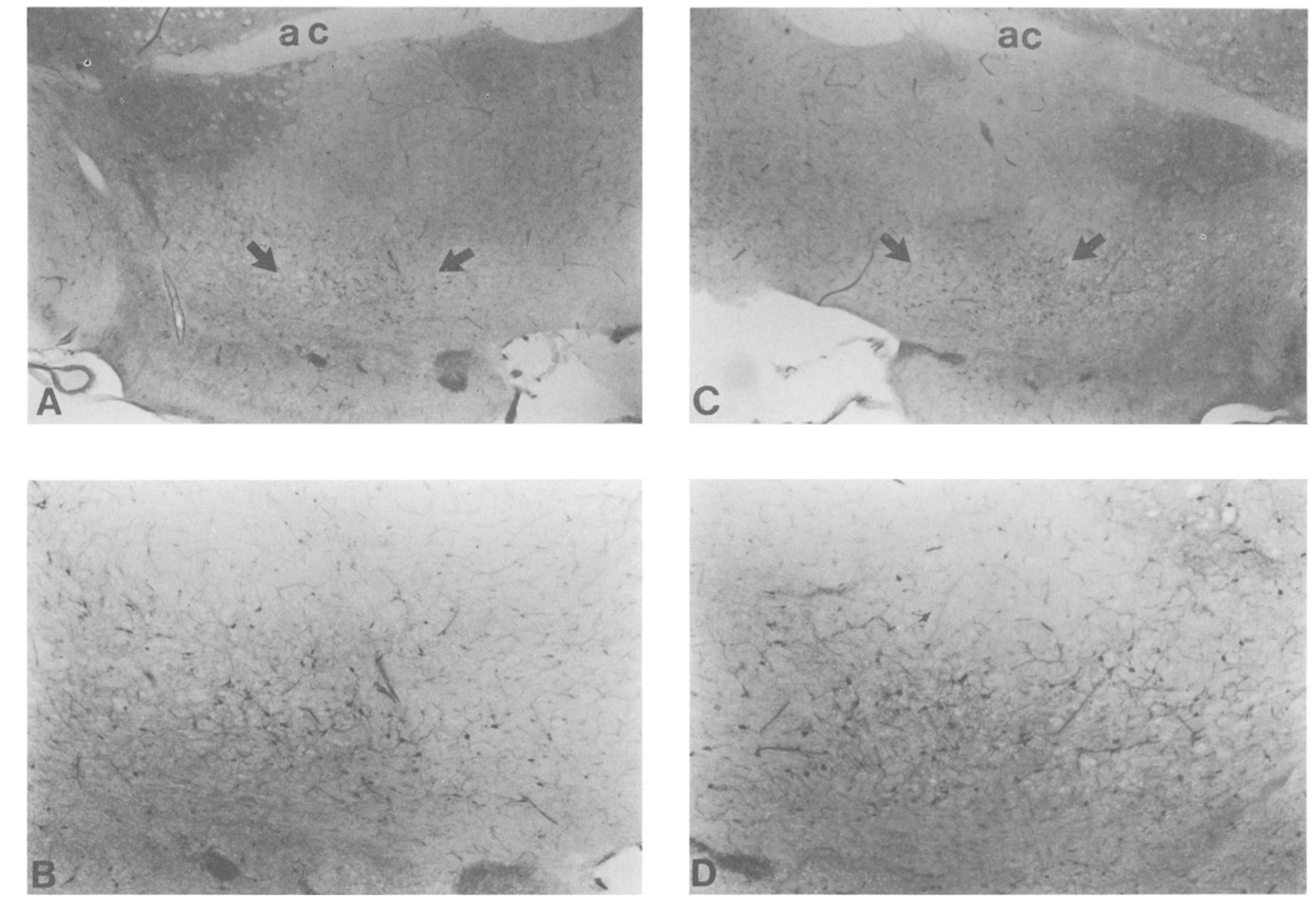

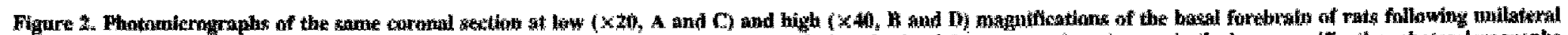

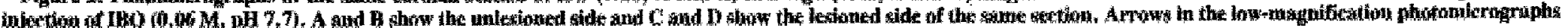

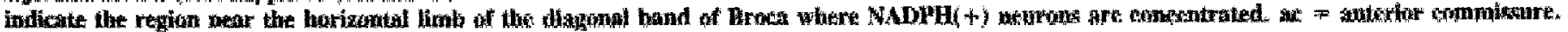


a significant and prolonged learning and memory deficit (Connor et al., 1991; Dunnett, Whishaw, Jones, \& Bunch, 1987; Markowska, Wenk, \& Olson, 1990; Page et al., 1991; Riekkinen et al., 1991; Robbins et al., 1989; Wenk et al., 1989). In a recent study, we found that manipulation of IBO's cytotoxicity by CYS or Zn can attenuate the performance deficit in a task that requires learning and memory (Wenk et al., 1992).

In addition to the basal forebrain cholinergic cells, $\mathrm{NADPH}(+)$ cells were also differentially vulnerable to the effects of IBO and QUIS. Injection of QUIS, but not IBO, resulted in a loss of NADPH( +) cells throughout the basal forebrain region. These results are consistent with a recent study (Ferriero \& Simon, 1991) that also found that NADPH $(+)$ neurons within the striatum are vulnerable to QUIS and AMPA. The differential loss of neurons may be related to the ability of different glutamate analogues to produce the cytotoxic NO molecule (Bredt \& Snyder, 1992). Increased NO production can also lead to increased cyclic guanosine monophosphate (cGMP) levels (Bredt \& Snyder, 1989; Dawson et al., 1991; Frandsen et al., 1991; Kiedrowski et al., 1992). In both cortical and cerebellar neuronal cell cultures, exposure to an NMDA agonist stimulated the conversion of arginine to citrulline, thus releasing NO, and increased cGMP. Additionally, treatment of cortical cultures with 8-Br-cGMP, a nonhydrolyzable cGMP analogue, potentiated the toxicity of NMDA (Frandsen et al., 1991). This suggests that when stimulated with an NMDA agonist (e.g., IBO), NADPH( +) neurons are somehow protected from the cytotoxic effects of their own increased production of NO and regional increases in cGMP levels. In contrast, these neurons are not protected from the cytotoxic processes initiated by QUIS. Furthermore, these results suggest a potential mechanism to explain why IBO produces a greater degree of gliosis and nonspecific damage within the injection site than does QUIS (Dunnett et al., 1987; Sarter \& Dudchenko, 1991): IBO has the ability to generate NO and spare NO-producing cells, whereas QUIS destroys these NO-producing cells.

In conclusion, these studies suggest that the cytotoxic actions of QUIS are not specific to the cholinergic neurons within the basal forebrain-that is, QUIS was able to effectively destroy both cholinergic and NADPH( +) cells within the extent of the injection site. In contrast, IBO destroyed a smaller percentage of cholinergic cells, relative to QUIS, but did not destroy NO-synthesizing [NADPH(+)] cells. Our recent report (Wenk et al., 1992) demonstrated that while only IBO produced a long-lasting working memory impairment, neither IBO or QUIS differentially destroyed somatostatin-, neurotensin-, substance $P_{-}$, leu-enkephalin-, or $\gamma$-amino-butyric acidcontaining basal forebrain cells. Taken together, the results of these two studies suggest the following hypothesis to explain the differential behavioral effects of these two toxins: IBO exposure leads to the production and release of NO from NADPH $(+)$ cells within the basal forebrain and to the destruction of an unidentified nearby noncholinergic cell group, whereas QUIS exposure destroys the NO-producing cells, thus leaving this unidentified basal forebrain system intact.

Glutamate excitotoxicity has been implicated in a variety of neuropathological states, such as ischemia, epilepsy, and Alzheimer's disease (Olney, 1989). By manipulating the cytotoxicity of specific glutamate analogues, investigators may gain insight into the cellular processes that determine the differential vulnerability of specific cell populations, which might suggest novel approaches to effective pharmacotherapies.

\section{REFERENCES}

Araki, M., McGeer, P. L., McGeer, E. G. (1985). Differential effect of kainic acid on somatostatin, gabaergic and cholinergic neurons in the rat striatum. Neuroscience Letters, 53, 197-202.

Bartus, R. T., Dean, R. L., Beer, B., Lippa, A. S. (1982). The cholinergic hypothesis of geriatric memory dysfunction. Science, 217, 408-417.

Beal, M. F., Kowall, N. W., Swartz, K. J., Ferrante, R. J., a Martin, J. B. (1989). Differential sparing of somatostatinneuropeptide $\mathrm{Y}$ and cholinergic neurons following striatal excitotoxin lesions. Synapse, 3, 38-47.

BredT, D. S., \& SNYDER, S. H. (1989). Nitric oxide mediates glutamatelinked enhancement of cGMP levels in the cerebellum. Proceedings of the National Academy of Sciences, USA, 86, 9030-9033.

BREDT, D. S., \& SNYDER, S. H. (1992). Nitric oxide, a novel neuronal messenger. Neuron, 8, 3-11.

Bridges, R. J., Koh, J. Y., Hatalski, C. G., Cotman, C. W. (1991) Increased excitotoxic vulnerability of cortical cultures with reduced levels of glutathione. European Journal of Pharmacology, 192, 199-200.

CHOI, D. W. (1987). Ionic dependence of glutamate neurotoxicity. Journal of Neuroscience, 7, 369-379.

Connor, D. J., Langlais, P. J., \& Thal, L. J. (1991). Behavioral impairments after lesions of the nucleus basalis by ibotenic acid and quisqualic acid. Brain Research, 555, 84-90.

Coyle, J. T., Price, D. L., Delong, M. R. (1983). Alzheimer's disease: A disorder of cortical cholinergic innervation. Science, 219, $1184-1190$

Coyle, J. T., SChWARCz, R. (1983). The use of excitatory amino acids as selective neurotoxins. In A. Bjorklund \& T. Hokfelt, (Eds.), Handbook of chemical neuroanatomy: Vol.1. Methods in chemical neuroanatomy (pp. 508-527). New York: Elsevier.

Dawson, V. L., Dawson, T. M., London, E. D., Bredt, D. S., \& SNYDER, S. H. (1991). Nitric oxide mediates glutamate neurotoxicity in primary cortical cultures. Proceedings of the National Academy of Sciences, USA, 88, 6368-6371.

Dunnet, S. B., Whishaw, I. Q., Jones, G. H., Bunch, S. T (1987). Behavioral, biochemical and histochemical effects of different neurotoxic amino acids injected into nucleus basalis magnocellularis of rats. Neuroscience, 20, 653-669.

Ferriero, D. M., SimON, R. P. (1991). Neonatal striatal NADPHdiaphorase neurons are vulnerable to quisqualate and its analogue alphsamino-3-hydroxy-5-methyl-4-isoxazole proprionate (AMPA). Neuroscience Letters, 126, 52-56.

Finn, S. F., Swartz, K. J., Beal, M. F. (1991). 2-chloroadenosine attenuates NMDA, kainate, and quisqualate toxicity. Neuroscience Letters, 126, 191-194.

FonNum, F. (1969). Radiochemical micro assays for the determination of choline acetyltransferase and acetylcholinesterase activities. Biochemistry Journal, 115, 465-472.

Frandsen, A., Anderson, C. F., Schousboe, A. (1991). Possible role of cGMP in excitatory amino acid induced cytotoxicity in cultured cerebral cortical neurons. Neurochemical Research, 17, 35-43.

GarthwaIte, G., \& GARThwaIte, J. (1989). Differential dependence on $\mathrm{Ca}^{2+}$ of $\mathrm{N}$-methyl-D-aspartate and quisqualate neurotoxicity in young rat hippocampal slices. Neuroscience Letters, 7, 316-322.

Garthwaite, G., Garthwaite, J. (1991). AMPA neurotoxicity in 
rat cerebellar and hippocampal slices: Histological evidence for three mechanisms. European Journal of Neuroscience, 3, 715-728.

Kiedrowski, L., Cost A, E., \& Wroblewski, J. T. (1992). Glutamate receptor agonists stimulate nitric oxide synthase in primary cultures of cerebellar granule cells. Journal of Neurochemistry, 58, 335-341.

Kон, J. Y., \& CHOI, D. W. (1988). Vulnerability of cultured cortical neurons to damage by excitotoxins: Differential susceptibility of neurons containing NADPH-diaphorase. Journal of Neuroscience, $\mathbf{8}$, 2153-2163.

Lamour, Y., Dutar, P., Jobert, A. (1982). Topographic organization of basal forebrain neurons projecting to the rat cerebral cortex. Neuroscience Letters, 34, 117-122.

MarkowsKa, A. L., Wenk, G. L., \& Olton, D. S. (1990). Nucleus basalis magnocellularis and memory: Differential effects of two neurotoxins. Behavioral \& Neural Biology, 54, 13-26.

Mesulam, M.-M., Mufson, E. J., Levey, A. I., \& Wainer, B. H. (1983). Cholinergic innervation of cortex by the basal forebrain: Cytochemistry and cortical connections of the septal area diagonal band nuclei, nucleus basalis (substantia innominata) and hypothalamus in the rhesus monkeys. Journal of Comparative Neurology, 214, 170-197.

Murphy, T. H., Miyamoto, M., Sastre, A., SchnaAr, R. L., \& COYLE, J. T. (1989). Glutamate toxicity in a neuronal cell line involves inhibition of cystine transport leading to oxidative stress. $\mathrm{Neu}$ ron, 2, 1547-1558.

Murphy, T. H., SChnaAR, R. L., \& Coyle, J. T. (1990). Immature cortical neurons are uniquely sensitive to glutamate toxicity by inhibition of cystine uptake. FASEB, 4, 1624-1633.

Nadler, J. V., Evenson, D. A., \& Cuthbertson, G. J. (1981). Comparative toxicity of kainic acid and other acidic amino acids toward rat hippocampal neurons. Neuroscience, 6, 2505-2517.

OlNEY, J. W. (1989). Excitatory amino acids and neuropsychiatric disorders. Biological Psychiatry, 26, 505-525.

Olton, D. S., \& WENK, G. L. (1987). Dementia: Animal models of the cognitive impairments produced by degeneration of the basal forebrain cholinergic system. In H. Y. Meltzer (Ed.), Psychopharmacology: The third generation of progress (pp. 941-953). New York: Raven.

Page, K. J., Everitt, B. J., Robbins, T. W., Marston, H. M., \& Wilkinson, L. S. (1991). Dissociable effects on spatial maze and passive avoidance acquisition and retention following ampa- and ibotenic acid-induced excitotoxic lesions of the basal forebrain in rats: Differential dependence on cholinergic neuronal loss. Neuroscience, 43, 457-472.

Pasqualotto, B. A., \& Vincent, S. R. (1991). Galanin and NADPHdiaphorase coexistence in cholinergic neurons of the rat basal forebrain. Brain Research, 551, 78-86.

Perkins, M. N., \& Stone, T. W. (1983). Quinolinic acid: Regional variations in neuronal sensitivity. Brain Research, 259, 172-176.

Peters, S., Кон, J., \& CHOI, D. W. (1987). Zinc selectivity blocks the action of N-methyl-D-aspartate on cortical neurons. Science, 236, 589-593.

Riekkinen, M. P., Riekkinen, P., \& Riekkinen, P., JR. (1991). Comparison of quisqualic and ibotenic acid nucleus basalis magnocellularis lesions on water-maze and passive avoidance performance. Brain Research Bulletin, 27, 119-123.

Robbins, T. W., Everitt, B. J., Marston, H. M., Wilkinson, J., JoNES, G. H., \& PAGE, K. J. (1989). Comparative effects of ibotenic acid-and quisqualic acid-induced lesions of the substantia innominata on attentional function in the rat: Further implications for the role of the cholinergic neurons of the nucleus basalis in cognitive processes. Behavioral Brain Research, 35, 221-240.

Rothman, S. M., OLNEy, J. W. (1987). Excitotoxicity and the NMDA receptor. Trends In Neuroscience, 10, 299-302.

Rye, D. B., Wainer, B. H., Mesulam, M.-M., Mufson, E. J., \& SAPER, C. B. (1984). Cortical projections arising from the basal forebrain: A study of cholinergic and noncholinergic components employing combined retrograde tracing and immunohistochemical localization of choline acetyltransferase. Neuroscience, 13, 627-643.

Sarter, M., a Dudchenko, P. (1991). Dissociative effects of ibotenic and quisqualic acid-induced basal forebrain lesions on cortical acetylcholinesterase-positive fiber density and cytochrome oxidase activity. Neuroscience, 41, 729-738.

Scherer-Singler, U., Vincent, S. R., Kimura, H., \& McGeer, E. G. (1983). Demonstration of a unique population of neurons with NADPH-diaphorase histochemistry. Journal of Neuroscience Methods, 9, 229-234.

SChwarcz, R., Kohler, C. (1983). Differential vulnerability of central neurons of the rat to quinolinic acid. Neuroscience Letters, 38 , 85-90.

VinCENT, S. R., HoPE, B. T. (1992). Neurons that say NO. Trends in Neurosciences, 15, 108-113.

Vincent, S. R., Johansson, O., Hokfelt, T., Skirboll, L., Elde, R. P., Terenius, L., Kimmel, J., \& Goldstein, M. (1983). NADPHdiaphorase: A selective histochemical marker for striatal neurons containing both somatostatin- and avian pancreatic polypeptide (APP)like immunoreactivities. Journal of Comparative Neurology, 217, 252-263.

VINCENT, S. R., \& KIMURA, H. (1992). Histochemical mapping of nitric oxide synthase in the rat brain. Neuroscience, 46, 755-784.

Waldvogel, H. J., Faull, R. L. M., Williams, M. N., \& Dragunow, M. (1991). Differential sensitivity of calbindin and parvalbumin immunoreactive cells in the striatum to excitotoxins. Brain Research, 546, 329-335.

Wenk, G. L., CribBs, B., \& MCCALL, L. (1984). Nucleus basalis magnocellularis: Optimal coordinates for selective reduction of choline acetyltransferase in frontal neocortex by ibotenic acid injections. $E x$ perimental Brain Research, 56, 335-340.

Wenk, G. L., Harrington, C. A., Tucker, D. A., Rance, N. E., \& WALKER, L. C. (1992). Basal forebrain neurons and memory: A biochemical, histological and behavioral study of differential vulnerability to ibotenate and quisqualate. Behavioral Neuroscience, 106, 909-923.

Wenk, G. L., Markowska, A. L., \& Olton, D. S. (1989). Basal forebrain lesions and memory alterations in neurotensin, not acetylcholine, may cause amnesia. Behavioral Neuroscience, 103, 765-769.

Westbrook, G. L., \& MAYER, M. L. (1987). Micromolar concentrations of $\mathrm{Zn}^{2+}$ antagonize NMDA and GABA responses of hippocampal neurons. Nature, 328, 640-643.

Yeh, G.-C., Bonhaus, D. W., \& McNamara, J. O. (1990). Evidence that zinc inhibits $\mathrm{N}$-methyl-d-aspartate receptor-gated ion channel activation by noncompetitive antagonism of glycine binding. Molecular Pharmacology, 38, 14-19.

(Manuscript received August 25, 1992; revision accepted for publication September 9, 1992.) 